Rev. Adm. Saúde - Vol. 18, № 71, abr. - jun. 2018

http://dx.doi.org/10.23973/ras.71.107

ARTIGO ORIGINAL

\title{
Liderança em enfermagem na perspectiva de enfermeiros assistenciais de um hospital público da tríplice fronteira
}

Treating nurses outlook on nursing leadership at a public hospital of the triple borde

\section{Vanessa Bordin', Maria de Lourdes de Almeida², Adriana Zilly ${ }^{3}$, Eveline Treméa Justino ${ }^{4}$, Nelise Dias Vieira da Silva ${ }^{5}$, Jossiana Wilke Faller ${ }^{6}$}

1. Enfermeira. Residente de enfermagem do Hospital Universitário do Oeste do Paraná

2. Enfermeira, doutora em enfermagem. Professora colaboradora no Programa de PósGraduação em Saúde Pública em Região de Fronteira, Foz do Iguaçu PR

3. Bióloga, doutora em ciências biológicas. Docente do curso de enfermagem da UNIOESTE, Foz do Iguaçu PR

4. Enfermeira, doutoranda em enfermagem em saúde pública. Docente efetiva do curso de enfermagem da Universidade Estadual do Oeste do Paraná, Foz do Iguaçu PR

5. Enfermeira

6. Enfermeira, mestre em enfermagem. Professora efetiva do curso de enfermagem da Universidade Estadual do Oeste do Paraná

\section{RESUMO}

Objetivo: Objetivou-se caracterizar a percepção de enfermeiros que atuam na assistência de um hospital público sobre a liderança e identificar dificuldades encontradas para exercê-la. Material e métodos: Pesquisa qualitativa do tipo descritiva-exploratória realizada em um hospital público na cidade de Foz do Iguaçu-PR, com amostra intencional de 31 enfermeiros, no primeiro semestre de 2012. Resultados e discussão: A análise dos dados, por meio da técnica do Discurso do Sujeito Coletivo (DSC), propiciou a construção de nove DSC mediante nove Ideias Centrais (IC) a partir de dois temas. Referentes à 
percepção de liderança para o enfermeiro: liderança é você influenciar os colaboradores para alcançar os objetivos; liderança é você gerenciar, administrar o setor e sua equipe. Do tema dificuldades para exercer a liderança, teve-se sete ICs e respectivos DSCs: tenho dificuldade com os diferentes tipos de personalidades; sou recém-formada; não sei administrar meu tempo; sobrecarga de trabalho; sou muito paternalista com a equipe; eu tenho dificuldade em impor; A minha dificuldade é comunicação. Conclusões: Com esse estudo, espera-se motivar o enfermeiro para a compreensão da liderança como ferramenta gerencial na sua prática cotidiana, e contribuir para a melhoria do perfil de liderança dos enfermeiros na instituição.

Palavras-chave: pesquisa em administração de enfermagem; administração de serviços de saúde; competência profissional; liderança.

\begin{abstract}
Objective: The study aimed at characterizing the perception on leadership of treating nurses working at a public hospital and at identifying difficulties they found during the working process. Material and methods: The present descriptive-exploratory study of qualitative approach has been outlined during the first semester of 2012 at a public hospital at Foz de lguaçu-PR, with an intentional sample composed by 31 nurses. Results and discussion: The data analysis performed by the Discourse of the Collective Subject (DCS) provided developing nine DCS from nine central ideas $(\mathrm{Cl})$ and based on two themes. The following were the references for leadership awareness of nurses: Leadership means to influence employees in order to aim goals; Leadership is managing and supervising the sector and team. Seven Cls and its DCSs came out from the theme difficulties to leadership: I have problems with the different kind of personalities; I just majored; I do not know how to manage my time; Overload of work; I use the paternalistic style with the team; I have difficulties on imposing; Communicating is difficult for me. Conclusions: The prospective study intends to motivate nurses to understand leadership as a managerial tool on a day-to-day practice; and to contribute to improving nurse's leadership profile at the institution.
\end{abstract}

Keywords: nursing administration research; health services administration; professional competence; leadership.

\title{
INTRODUÇÃO
}

Para o trabalho gerencial do enfermeiro, as competências e habilidades gerenciais precisam ser apreendidas desde sua formação acadêmica e materializadas em sua prática profissional diária. No Brasil, no que diz respeito 
às políticas de educação têm-se as Diretrizes Curriculares Nacionais do Curso de Graduação em Enfermagem (DCNs), que descrevem que essas habilidades compreendem: tomada de decisões; comunicação; liderança; administração e gerenciamento, e educação permanente. ${ }^{1}$

A liderança para o enfermeiro fundamenta o trabalho com a equipe multiprofissional, sendo que este profissional deve estar qualificado para assumir posições de liderança nessas equipes. ${ }^{2} \mathrm{O}$ desempenho de um grupo de trabalho é influenciado pelo comportamento do líder, no qual a equipe se espelha e busca um modelo para a execução de suas práticas profissionais. $\mathrm{Na}$ rotina de trabalho da enfermagem, o líder determina quando adotar comportamentos e atitudes diversas a fim de envolver e comprometer sua equipe. $^{3}$

Essa capacidade de influenciar pessoas acontece quando a credibilidade do líder for notada pelos seus seguidores. Essa conquista vai depender do esforço pessoal pela busca do conhecimento e pelo aperfeiçoamento de habilidades e técnicas, por meio da comunicação, da resolução de conflitos e pela tomada de decisões assertivas. ${ }^{4}$

Os enfermeiros, independentemente de ocuparem cargos na assistência ou gerência e do setor em que trabalham, devem conhecer e apropriar-se das competências gerenciais que Ihes são cabíveis, uma vez que, com frequência, ocuparão um lugar de liderança na equipe.

Uma pesquisa realizada com enfermeiras em um hospital de grande porte na região sul do Brasil, revelou que apesar das enfermeiras considerarem a liderança uma competência importante no dia a dia, estas apresentam grande dificuldade em compreender o significado da mesma. Para o enfermeiro, a liderança contribui no alcance dos objetivos, como o cuidado de qualidade aos usuários e a capacidade em influenciar a sua equipe. ${ }^{5}$

Concomitantemente à liderança, na prática profissional do enfermeiro, o gerenciamento em enfermagem está presente em todos os níveis de atenção à saúde, pois é uma ferramenta de organização dos serviços que tem como objetivo primordial a qualidade da assistência prestada ao indivíduo, família e comunidade. ${ }^{6}$

Diante dessas considerações, buscou-se conhecer a percepção sobre liderança que enfermeiros assistenciais de um hospital público vivenciam em sua prática profissional. Desta forma, desenhou-se o seguinte problema de pesquisa: Qual a percepção do enfermeiro que atua na assistência de um hospital público tem sobre liderança?

Para responder esse questionamento, esta pesquisa teve como objetivos caracterizar a percepção de enfermeiros que atuam na assistência de um hospital público sobre a liderança e identificar as dificuldades encontradas por esses enfermeiros para exercer a liderança na sua prática profissional. 


\section{MATERIAL E MÉTODOS}

Trata-se de uma pesquisa com abordagem qualitativa do tipo descritivaexploratória, realizada no município de Foz do Iguaçu-PR com enfermeiros que atuam em um hospital público. Os enfermeiros pertenciam aos seguintes setores: Unidade de Clínica Médica, Unidade de Clínica Cirúrgica, Unidade de Ortopedia, Unidade de Pediatria, Unidade de Pronto Socorro, Unidade de Terapia Intensiva de Adulto e Unidade de Terapia Intensiva Pediátrica.

A população do estudo constituiu-se de 39 enfermeiros assistenciais atuantes no referido hospital, abrangendo os diferentes turnos de atuação da assistência. Destes, foram incluídos na pesquisa todos os enfermeiros que concordaram em participar do estudo, totalizando 31 enfermeiros. Respeitandose os critérios de exclusão da pesquisa, quatro enfermeiros não aceitaram participar e os demais estavam de férias ou folga durante o período de coleta dos dados.

A coleta de dados foi realizada entre o período de fevereiro a março de 2012, após realização de pré-teste para validação do instrumento de coleta de dados. Como técnica, utilizou-se entrevista semiestruturada com uso de um roteiro com questões que guiaram a coleta. A entrevista foi realizada em local de trabalho desses enfermeiros no qual o anonimato foi preservado. As entrevistas foram gravadas com a autorização dos entrevistados e transcritas posteriormente.

Os autores seguiram as recomendações da Resolução 196/1996 do Conselho Nacional de Saúde ${ }^{7}$ e a pesquisa foi submetida e aprovada pelo Comitê de Ética e Pesquisa em Seres Humanos (CEP/UNIOESTE), sob Parecer 1448/2011 e CR1448/2011. A coleta de dados ocorreu após a entrega do termo de consentimento livre e esclarecido pelo pesquisador aos sujeitos da pesquisa e esclareceu-se sobre as informações do documento.

Os dados foram tabulados e analisados utilizando estatística descritiva e a análise dos depoimentos por meio da técnica do Discurso do Sujeito Coletivo (DSC). ${ }^{8}$

O DSC é uma técnica utilizada para organizar e tabular os dados de uma pesquisa qualitativa na qual são analisados depoimentos individuais que expressem o pensamento de uma coletividade. Nesta técnica de análise de dados, procura-se o resgate do sentido das opiniões coletivas que terminam em discursos coletivos, isto é, os DSC. Este é um processo complexo, subdivido em momentos variados e efetuados por operações realizadas sobre o material verbal que foi coletado na pesquisa. ${ }^{9}$

Dos depoimentos extraem-se as Ideias Centrais (ICs), as Expressões-Chave (E-Ch), a Ancoragem (AC) e os discursos particulares que serão a base para a construção dos DSC. Sendo assim, as ICs são fórmulas sintéticas que irão descrever os sentidos dos encontrados nos no material verbal de cada resposta e ainda nos conjuntos de respostas de diferentes. ${ }^{9}$ Nesse estudo optou-se em não utilização das ACs. 
Diferentemente das ICs, as Ancoragens são formulas sintéticas que descrevem as ideologias, valores e crenças presentes no material verbal das respostas individuai ou das agrupadas na forma de afirmações genéricas que tem como função enquadrar situações específicas. Vale lembrar que na técnica do DSC é considerado as ancoragens somente quando existe no material marcas discursivas explicitas dessas afirmações. As ECs são trechos, pedações ou transcrições literais dos discursos que descrevem da melhor maneira os conteúdos dos depoimentos. ${ }^{8}$

Os DSCs propriamente ditos são a reunião das E-Ch encontradas nos depoimentos que possuem ICs e ou ACs de sentido semelhante ou que se complementam. Essas E-Chs que tem sentido semelhante formam depoimentos coletivos, redigidos na primeira pessoa do singular para enfatizar a presença do pensamento coletivo na pessoa de um sujeito coletivo de discurso. ${ }^{9}$

Em síntese, após junção dos discursos individuais cria-se o pensamento de uma coletividade. Todos os passos descritos foram seguidos durante a coleta, análise e tabulação dos dados qualitativos. ${ }^{8}$

\section{RESULTADOS E DISCUSSÃO}

Dos 31 enfermeiros assistenciais que participaram da pesquisa, 21 (67,75\%) eram do sexo feminino e $18(58,06 \%)$ eram solteiros. Quanto à faixa etária, prevaleceu a idade de 23 a 29 anos de $18(58,06 \%)$ sujeitos, seguida de 10 $(32,26 \%)$ com 30 a 39 anos e apenas 3 enfermeiros $(9,68 \%)$ com idade superior a 40 anos.

No quesito jornada de trabalho, $25(80,25 \%)$, enfermeiros trabalham na escala de $12 \times 36$ horas e apenas 6 enfermeiros (19,35\%) trabalham mais que 12 horas ao dia. Dos 31 enfermeiros, 18 trabalham no período diurno (58,06\%), e 13 no período noturno $(41,94 \%)$. Quando questionados sobre outros vínculos de trabalho, 8 enfermeiros $(25,81 \%)$ o possuíam, um dado importante, pois jornadas de trabalho excessivas colaboram para o estresse e baixo rendimento do profissional.

A seguir apresentam-se os resultados da construção dos DSC e suas Ideias Centrais (IC) correspondentes, obtidas por meio das entrevistas que compuseram a matéria-prima desses discursos. Na análise geral das IC e DSC que emergiram dos depoimentos dos sujeitos, surgiram nove ICS e DSCs correspondentes, a partir das duas questões norteadoras (Tabela 1).

Tabela 1. Quadro geral das IC dos DSC, Foz do Iguaçu-PR, 2012.

Apresentação geral das questões da entrevista e IC 
Questão 1: O que é liderança para você?

Questão 2: Quais são suas dificuldades para exercer a liderança na sua prática profissional?
IC1: Liderança é influenciar os colaboradores para alcançar os objetivos.

IC2: Liderança é você gerenciar o setor e sua equipe.

IC3: Tenho dificuldade com os diferentes tipos de personalidades.

IC4: Sou recém-formada.

IC5: Não sei administrar meu tempo.

IC6: Sobrecarga de trabalho.

IC7: Sou muito paternalista com a equipe.

IC8: Eu tenho dificuldade em impor.

IC9: A minha dificuldade é comunicação.

$\mathrm{Na}$ questão norteadora sobre a percepção da liderança pelo enfermeiro obtevese como ICs: Liderança é você influenciar os colaboradores para alcançar os objetivos; Liderança é você gerenciar, administrar o setor e sua equipe. Segue a IC 1 e o DSC 1.

Quadro 1. Apresentação da IC 1 e DSC 1 referente a questão de número 1 dos depoimentos de enfermeiros de um hospital público de Foz do Iguaçu-PR, 2012.

\begin{tabular}{|l|}
\hline IDEIA CENTRAL 1 \\
\hline Liderança é você influenciar os colaboradores para alcançar os objetivos. \\
\hline DISCURSO DO SUJEITO COLETIVO 1 \\
\hline $\begin{array}{l}\text { Para mim, liderança não é mandar e nem apenas delegar e atribuir } \\
\text { funções, é fazer com que aquelas pessoas que estão sob a sua } \\
\text { responsabilidade façam o que você quer, mas de maneira gostosa, leve e } \\
\text { livre. O líder é aquele que consegue cativar, aquele que tem um vínculo } \\
\text { com a equipe. Você impõe de uma forma indireta, você conversa com sua } \\
\text { equipe e assim, eles irão querer fazer por espontânea vontade não por } \\
\text { espontânea pressão, a partir do seu trabalho. Eles fazem as atividades } \\
\text { porque é necessário e concordam com o meu tipo de pensamento, não por } \\
\text { uma obrigação, pois, o líder não é aquele que impõe. Eu tenho que ser o } \\
\text { exemplo fazendo as atividades corretamente para influenciá-los de forma } \\
\text { positiva. A verdadeira liderança é quando a pessoa faz porque gosta do } \\
\text { que está fazendo e porque o líder lhe passou isso. Eu lidero a minha }\end{array}$ \\
\hline
\end{tabular}


equipe de uma forma que eles consigam desenvolver o papel sem a minha supervisão, sem eu estar presente todo o tempo. Eu preciso saber direcionar e orientar a minha equipe para o que deve ser feito, quando eu peço algo quero que o funcionário acate aquilo sem resistência, isso é liderança. Também faz parte da liderança atingir os objetivos as expectativas do meu setor e da empresa, desenvolver o trabalho com eficiência. Eu preciso saber conduzir a equipe conforme os pensamentos institucionais e princípios éticos, sempre trabalhando junto com eles para ter um bom resultado, focando no paciente.

No DSC 1, o enfermeiro percebe que em sua forma de liderar não deve ordenar, mas influenciar o grupo para que as atividades sejam realizadas e as tarefas cumpridas. Ele entende que é necessário ser o exemplo para seus colaboradores. O sujeito do discurso coletivo quer que seus funcionários desempenhem as atividades mesmo em sua ausência, além de ressaltar a importância de seguir os princípios éticos e institucionais da empresa. Nesse discurso, o enfermeiro coloca como liderança os objetivos instituicionais, e transfere isso para a sua equipe.

Quando o enfermeiro exerce a influência da liderança de forma negativa, permite aos liderados questionarem seu poder e saber de enfermagem. Como consequência, mudanças de hábitos, interação da equipe e relacionamento social podem ocorrer. Assim, quanto mais a enfermeira estabelece relações de poder administrativo e burocrático com a sua equipe, reduz seu poder e saber de enfermagem a ser compartilhado com a mesma. ${ }^{10}$

A segunda IC e DSC respectivo são apresentados no quadro abaixo.

Quadro 2. Apresentação da IC 2 e DSC 2 referentes a questão de número 1 dos depoimentos de enfermeiros de um hospital público de Foz do Iguaçu-PR, 2012.

\section{IDEIA CENTRAL 2}

Liderança é você gerenciar, administrar o setor e sua equipe.

\section{DISCURSO DO SUJEITO COLETIVO 2}

Liderança é saber gerenciar, administrar, não somente as questões de assistência mais também às administrativas. Comandar o setor como um todo. Liderança é o ato de organizar, saber programar a assistência e supervisionar a equipe que você trabalha. Saber administrar o tempo do trabalho. Liderança é uma ação de coordenar a equipe, estar à frente da equipe, ser responsável pela equipe, passar segurança. Não basta só querer liderar se você não for o espelho da equipe, o líder é uma peça chave principal da equipe, é um guia, vai nortear, orientar, distribuir, organizar. Eu determino algumas coisas em prol dos pacientes e também 
tem que estar em prol da equipe. Eu tenho que destinar cada um para uma função, você vai fazer isso, você vai fazer aquilo, tenho também que motivar e acompanhar na assistência, estar sempre presente e participando nos procedimentos, trabalhar em equipe, advertir se tiver alguma coisa errada, sempre dar apoio para que eles tenham credibilidade em você. Sempre administrar e resolver conflitos e as dificuldades da equipe, sempre estar participando, interagindo e tirando dúvidas, ouvir a equipe, escutar a opinião deles e planejar junto a eles, as decisões que tem que ser tomadas no setor.

Ao analisar o DSC 2, nota-se que para esses sujeitos, liderar é o mesmo que administrar, gerenciar e trabalhar em equipe. O enfermeiro desse discurso descreve o seu estilo de liderança como participativo e preocupa-se com o desempenho das atividades de seus colaboradores, por isso a necessidade de supervisionar. Evidencia-se desta forma, que há um controle das tarefas, uma situação presente nas gerências com base das teorias tradicionais da administração, como o Taylorismo/Fordismo, que contradiz o estilo de liderança citado nesse DSC.

O modelo de gestão predominante nos dias de hoje no ocidente é a gestão clássica, ou mecanicista, o que pode explicar a forma como os serviços de saúde são organizados e gerenciados, sejam em instituições públicas ou serviços privados. ${ }^{11}$

O enfermeiro, no contexto atual, é motivado a abstrair-se dessa visão burocrática e tradicionalista centrada na gerência dos instrumentos de trabalho tais como controlar materiais e insumos e escalas de trabalho, dentre outros e incorporar em sua prática a gestão com novos referenciais como a definição de metas e objetivos, organização dos serviços, gerência dos sistemas de informação em saúde e avaliação de resultados. ${ }^{12}$

Apresenta-se no quadro 3 a IC 3 com o seu DSC 3.

Quadro 3. Apresentação da IC 3 e DSC 3 referentes a questão de número 2 dos depoimentos de enfermeiros de um hospital público de Foz do Iguaçu-PR, 2012.

\section{IDEIA CENTRAL 3}

Tenho dificuldade com os diferentes tipos de personalidades.

\section{DISCURSO DO SUJEITO COLETIVO 3}

Acredito que a diversidade das pessoas é uma dificuldade, cada um tem um comportamento, é difícil lidar com pessoas diferentes, têm uns funcionários com um gênio muito difícil, tem que saber lidar com todos para conseguir liderar, não são todos que aceitam ser liderados, comandados; cada um 
tem uma forma de aceitar regras e normas. Tem algumas coisas que você está impondo, está pedindo para que seja feita, eles acham que é melhor fazer de outra maneira, você tem que ter todo jogo de cintura para tratar cada um de uma forma especial, ter todo o cuidado no que vai falar, tem vezes que você fala uma palavra, alguma coisa e eles interpretam diferente, sempre tem aquele funcionário que te responde ou que não atende as regras do hospital e também as normas que você coloca no setor. Isso desanima porque você vai com uma ideia nova, uma ideia positiva e essa pessoa fala: eu vim aqui para fazer o que eu tenho que fazer e pronto, e você não tem instrumentos, ou não tem meios de convencer, ou tentar convencer essa pessoa a mudar de ideia, é difícil, isso é a pior parte.

O discurso DSC 3 evidencia a dificuldade que o enfermeiro nos relacionamentos interpessoais, pois vivencia seu cotidiano laboral com pessoas de diferentes personalidades. O discurso mostra também uma desmotivação por parte do enfermeiro em situações em que há falta de interesse da própria equipe, e que muitas vezes não detém ferramentas para mudar o quadro apresentado.

É necessário que a instituição assuma a sua parte nesse processo, de modo a propiciar condições para motivar o enfermeiro, melhorar sua autoestima e confiança e dessa forma motivar seus funcionários a desenvolver um trabalho em equipe, com melhoria da qualidade no cuidado prestado.

Esta situação é corroborada em outros cenários de trabalho de enfermagem. Estudo realizado em $2011^{13}$, menciona que os enfermeiros encontram dificuldades nas relações humanas, para exercer a liderança e por não sido capacitados para tal situação. Esse despreparo, para as relações sociais no trabalho é causa principal de estresse na equipe, além de falta de compromisso e desmotivação dos colaboradores, o que interfere diretamente na qualidade da assistência prestada. ${ }^{14}$

A seguir, o quadro com a IC 4 e DSC4.

Quadro 4. Apresentação da IC 4 e DSC 4 referentes a questão de número 2 dos depoimentos de enfermeiros de um hospital público de Foz do Iguaçu-PR, 2012.

\section{IDEIA CENTRAL 4}

Sou recém-formada.

\section{DISCURSO DO SUJEITO COLETIVO 4}

Eu acredito que a falta de experiência que temos quando iniciamos na profissão é o que me deixa um tanto quanto insegura, quando encaramos principalmente pessoas com tanta experiência, é um fator que dificulta um 
pouco, como eu trabalho com a equipe e eles são muito mais velhos do que eu, eles automaticamente têm uma autonomia e as vezes eles fazem as coisas primeiro para depois te comunicar, ou dependendo da maneira como você fala eles já interpretam de outra forma. A equipe tem pessoas que ainda são mais maleáveis e que entendem que se você está cobrando é porque precisa e tem outras que se você cobra ela fica falando isso para o resto da vida, nós cobramos no intuito de estar ajudando, de estar mostrando oh não é por aqui, não vai por aqui que você vai se dar mal, vai por aqui, mas tem gente que não admite isso. Como eu não sei muitas coisas na prática eu não tenho como me impor perante eles, como que eu vou pedir uma coisa que eu não sei fazer, que eu to aprendendo com eles, essa é minha maior dificuldade. No primeiro dia de trabalho foi bem complicado porque eu não sabia como chegar como me impor, mas isso foi trabalhado com o passar das semanas, dos meses, todos os dias nós vamos lidar com profissionais difíceis, tinha dificuldade desde abordar um funcionário quando ele falta até a forma de ele agir numa emergência, a minha dificuldade é que estuo aprendendo a liderar, mas eu vou conseguir.

No DSC 4, o enfermeiro recém-formado revela grande insegurança em liderar membros de sua equipe com idade superior à sua. A diferença de idade causa um grande impacto nesse sujeito, o que demonstra não consolidação da competência de liderar durante a sua formação acadêmica. O pouco conhecimento prático dificulta a autonomia e o exercício da autoridade necessária para a liderança, requisito indispensável na formação profissional do enfermeiro.

Estudos evidenciam que enfermeiros recém-formados têm dificuldade em desenvolver competências na forma de conhecimentos, habilidades e atitudes inerentes à prática gerencial na profissão, apesar destes terem sido trabalhados durante a graduação. Nessa pesquisa o autor coloca que as maiores dificuldades se relacionam ao campo das atitudes. ${ }^{15}$

Segue no quadro abaixo a IC 5 e DSC 5.

Quadro 5. Apresentação da IC 5 e DSC 6 referentes a questão de número 2 dos depoimentos de enfermeiros de um hospital público de Foz do Iguaçu-PR, 2012.

\begin{tabular}{|l|}
\hline IDEIA CENTRAL 5 \\
\hline Não sei administrar meu tempo. \\
\hline DISCURSO DO SUJEITO COLETIVO 5 \\
\hline $\begin{array}{l}\text { Tenho dificuldade pela falta de tempo, tenho muita dificuldade em estar } \\
\text { administrando meu tempo para poder encaixar, por exemplo, alguma } \\
\text { atividade extra, um exercício alguma coisa como na área do gerenciamento, }\end{array}$ \\
\hline
\end{tabular}


da liderança, tenho essa dificuldade de estar implantando pela falta de tempo mesmo. Mas o tempo nós aprendemos a administrar com o passar dos anos, das experiências que vamos adquirindo, vamos melhorando um pouco a administração do tempo, por exemplo, tem um funcionário novo, que é aquele colaborador que chegou e não teve treinamento nenhum e que eu preciso treinar, só que nem sempre tenho tempo, isso acaba dificultando um pouquinho para exercer a liderança, a falta de tempo principalmente com o colaborador novo, as vezes ele se sente um pouco abandonado, mas você precisa pegar na mão, ajudar fazer, ensinar, mostrar mesmo como que é feito da forma correta, ai você vai vendo que ele tem problemas que ele tem algumas dificuldades, que ele treme a mão na hora de fazer o procedimento igual a gente, ele treme, vamos, vou te ajudar, não precisa, não estou te avaliando, estou te ensinando hoje para daqui uns dias eu te cobrar, eu vou cobrar de você mas você já vai saber fazer da forma certa.

O sujeito do DSC 5 relaciona a dificuldade em liderar com a má administração do tempo e o pouco treinamento dos funcionários, o que poderia ser resolvida com educação permanente e continuada implantadas nas instituições de saúde.

Os enfermeiros possuem dificuldades para administrar o seu tempo de trabalho na rotina diária. Isso envolve a falta de planejamento, e tem como consequência a má distribuição do tempo para realizar as tarefas propostas e racionalizar o trabalho gerencial. Deste modo, a otimização do tempo disponível não ocorre, e o trabalho repetitivo e sem reflexão torna-se seu cotidiano. ${ }^{15}$

Dando seguimento na apresentação e análise dos dados, apresenta-se e discute-se a IC 6 e DSC 6.

Quadro 6. Apresentação da IC 6 e DSC 6 referentes a questão de número 2 dos depoimentos de enfermeiros de um hospital público de Foz do Iguaçu-PR, 2012.

\section{IDEIA CENTRAL 6}

Sobrecarga de trabalho.

\section{DISCURSO DO SUJEITO COLETIVO 6}

As dificuldades que enfrentei e eventualmente enfrento que refletem numa liderança as vezes um pouco desonesta, é ficar desfalcado realmente de funcionário aí você sobrecarrega aqueles que estão no plantão, a falta de funcionário, isso gera um pouco de estresse na tua equipe, mas eu vejo que quando acontece uma diminuição da equipe profissional e a sobrecarga de trabalho isso compromete um pouquinho na parte de gerenciamento. $\mathrm{O}$ 
fluxo de pacientes é grande isso dificulta um pouco estar liderando do jeito que gostaríamos, ou seja, estar supervisionando de maneira mais adequada estar cobrando de maneira mais eficaz seus funcionários, porque existe uma sobrecarga.

O sujeito do DSC 6 tem dificuldade em lidar com o subdimensionamento da equipe e a sobrecarga de trabalho. A utilização de conhecimentos sobre dimensionamento de pessoal em uma perspectiva ampliada, não é apenas uma ferramenta destinada para escalar seus funcionários, mas envolve desde a adequada caracterização das atividades previstas no setor, à negociação junto a instituição de saúde para a viabilização de locais adequados ao descanso desses profissionais em seus horários de pausa.

A sobrecarga de trabalho é um fator estressante para toda a equipe ocasionado pela demanda que a cada dia torna-se mais complexa. Além disso, o dimensionamento de pessoal pode interferir na qualidade, eficácia e o custo da atenção à saúde no contexto brasileiro, além de promover conflitos entre os profissionais, já que a equipe de enfermagem ainda representa o maior quantitativo de pessoal dos serviços de saúde no Brasil. ${ }^{16}$

A crise do modelo tradicional de administração impõe novas formas de enfrentar os desafios gerenciais no contexto corporativo. Desta forma, transforma o comprometimento das pessoas com o trabalho em uma condição imprescindível para alcance de melhores níveis de desempenho da equipe. ${ }^{17}$

Quando o enfermeiro desenvolve a competência liderança, pode ocorrer a diminuição no descontentamento por parte dos membros da equipe de enfermagem relacionados à jornada de trabalho e a remuneração, já que ele contribui com o envolvimento, satisfação e motivação na atividade profissional dos membros dessa equipe. ${ }^{18}$

No quadro abaixo, apresenta-se a IC 7 com o seu respectivo DSC 7.

Quadro 7. Apresentação da IC 7 e DSC 7 referentes a questão de número 2 dos depoimentos de enfermeiros de um hospital público de Foz do Iguaçu-PR, 2012.

\section{IDEIA CENTRAL 7}

Sou muito paternalista com a equipe.

\section{DISCURSO DO SUJEITO COLETIVO 7}

Eu me envolvo muito com meus colaboradores e acabo ajudando mais eles na assistência do que fazendo a minha parte como enfermeiro, tenho dificuldade porque sou muito paternalista, sou de ouvir bastante a minha equipe, sabe eu defendo demais a minha equipe, posso até algumas vezes passar a mão na cabeça demais, uma coisa que não é legal, eu 
preciso me policiar enfim, mas essa é uma característica minha é bem difícil perder, porque muitas vezes liderança é igual a educar a criança, você tem que dizer não, você tem que pegar na mão e mostrar como se faz, e as vezes você tem que cobrar, as vezes tem que ser enérgico, e nessa questão eu tenho dificuldade, quando eu vejo alguma coisa errada eu prefiro ir lá e fazer do que ficar cobrando, me enoja um pouco ter que cobrar coisas que o funcionário sabe que tem que ser feito, que é inerente a função, eu prefiro falar menos e fazer mais, devia ser ao contrário eu devia cobrar mais, mostrar mais sabe. Uma dificuldade minha também é fazer aquela crítica na hora que deve ser feita porque você convive num ambiente bom, temos uma boa relação, e quando chega ao ponto de estar fazendo uma crítica, chamando o funcionário ali no canto para conversar, eu tenho dificuldade, me sinto um pouco inseguro na hora de estar fazendo a crítica, de chamar atenção, de cobrar com mais rigidez, até dar uma advertência verbal ou por escrita se for o caso, dificuldade de chamar para conversa mais séria, mas não por isso que eu não faço, já fiz outras vezes, mas eu me sinto um pouco inseguro.

No DSC 7, o sujeito aponta como dificuldade o tipo de liderança que exerce, pois opta por uma liderança paternalista e a consequência dessa característica é a dificuldade para delegar funções e dar feedback. O enfermeiro apenas consente, inseguro em criticar e usar as normas disciplinares. Quando se refere a "fazer mais e falar menos" deixa claro sua dificuldade em delegar funções à equipe e tomar decisões quanto às normas disciplinares.

Ao analisar este discurso, deve-se levar em conta que a atuação do líder se reflete no desempenho do grupo de trabalho, visto que este na maioria das vezes busca uma figura para se espelhar como um modelo que acredita necessário para a execução de suas práticas de trabalho, do cuidado que é executado. $^{3}$

Pode-se dizer que, ao observar o comportamento desta equipe, também é possível inferir o estilo de liderança exercido pelo enfermeiro responsável, pois no cotidiano de trabalho da enfermagem, o líder adota comportamentos e atitudes diversas a fim de envolver e comprometer sua equipe. ${ }^{18}$

O quadro abaixo mostra mais uma IC e DSC que emergiu dos depoimentos dos enfermeiros entrevistados, a IC 8 e o DSC 8.

Quadro 8. Apresentação da IC 8 e DSC 8 referentes a questão de número 2 dos depoimentos de enfermeiros de um hospital público de Foz do Iguaçu-PR, 2012.

\section{IDEIA CENTRAL 8}

Eu tenho dificuldade em impor. 


\section{DISCURSO DO SUJEITO COLETIVO 8}

Eu tenho dificuldade em impor, não consigo ser grossa, não sou de impor a não ser que chegue ao meu limite, de falar, falar, falar, 3 vezes, 4 vezes e a pessoa não fazer, você acaba dando uma advertência para o funcionário para ele entender. Sou uma pessoa calma, já tenho essa naturalidade, com isso as pessoas acabam até levando para outro lado, ainda preciso de um pouco mais de autoridade para continuar sendo líder. Tenho muita dificuldade quando tem intercorrências porque os funcionários daqui fogem, é como se tapassem os ouvidos eles não me escutam, se estou chamando é porque é necessário, e essa é uma das minhas dificuldades, de liderar em emergências, até porque nossos funcionários não têm muito embasamento. Por não selecionar meus colaboradores, não consigo ter a liderança $100 \%$ da equipe.

Já no DSC 8, o sujeito coletivo associa a liderança com a imposição e grosseria, o que lhe garantiria o sucesso em desenvolver a autonomia para liderar. O discurso deixa clara a dificuldade do enfermeiro de liderar em situações de emergência.

O verdadeiro líder não se utiliza de imposição para liderar, mas são eficazes quando os outros os veem como tal, ouvindo suas ideias e as seguindo, pois concordam ou são influenciados pelo líder. ${ }^{19}$ As definições para liderança, autoridade e autoritarismo, muitas vezes são utilizadas erroneamente, o que torna necessário distingui-las. Estabelecer laços de confiança com os colaboradores pode auxiliar o enfermeiro em seu processo de trabalho, desenvolvido de maneira coerente entre a ação e o discurso do profissional. ${ }^{5}$ Pessoas com dificuldades para estabelecer uma relação harmônica em suas práxis acabam por perder a confiança e a credibilidade de sua equipe, abalando sua própria liderança. ${ }^{20}$

Para finalizar a apresentação dos resultados obtidos no discurso dos enfermeiros sobre a liderança, segue no quadro a IC 9 com o DSC9.

Quadro 9. Apresentação da IC 9 e DSC 9 referentes a questão de número 2 dos depoimentos de enfermeiros de um hospital público de Foz do Iguaçu-PR, 2012.

\section{IDEIA CENTRAL 9}

A minha dificuldade é a comunicação.

\section{DISCURSO DO SUJEITO COLETIVO 9}

Uma dificuldade que tenho é que não gosto de falar várias vezes, sou curta e grossa é meu hábito não gosto, eu falo uma vez e não gosto de ficar repetindo. Quando tenho que chamar atenção faço no horário 
adequado no lugar adequado, tudo o que você tem que falar para um funcionário seu você nunca fala perto do paciente, perto de familiar de paciente, perto de ninguém, você chama e conversa, você pede uma coisa e o funcionário não faz, pede novamente, está avisando que não esta sendo feito um bom trabalho e nada, então assim acho que minha maior dificuldade é essa. Quando acontece falha de comunicação você senta conversa pede para te explicar porque que ele acha que é melhor assim, às vezes você fala um protocolo como tem que ser e daqui uma semana, duas semanas eles estão fazendo de outra maneira, porque às vezes é mais fácil fazer da outra maneira e não seguir como o protocolo, tenho que conversar novamente, fazer reunião, tem os tópicos que colocamos, os tópicos que se perderam, sempre recolocado os tópicos para poder relembrar. Eu não gosto de ficar pedindo pra fazer as coisas as vezes eu acabo fazendo em vez de pedir só que esta errado mas isso eu estou me corrigindo, estou me policiando.

No DSC 9, o sujeito relata como obstáculo para exercer a liderança a dificuldade na comunicação com a equipe, competência gerencial do enfermeiro sem a qual a liderança não se concretiza. Esse sujeito tem dificuldade em delegar atividades, pois prefere fazê-las. No entanto, tem consciência dessa dificuldade.

Frente a isso, estudos indicam a necessidade de incorporar o diálogo nas relações interpessoais de enfermeiro e equipe e para melhorar o desempenho da liderança utilizam-se como instrumentos o diálogo, o consenso, compreensão, participação e o cuidado. ${ }^{13}$

No processo de trabalho gerencial do enfermeiro autores identificam a necessidade deste em desenvolver habilidades para a promoção de um ambiente positivo e conexão com a equipe de enfermagem para assegurar um processo comunicativo eficaz e atender as necessidades da unidade de trabalho e da instituição. ${ }^{20}$

Estudos mostram que os enfermeiros se preocupam com o caráter dinâmico que tem o processo de liderança, e na prática não se pode seguir um único estilo pois, há variações a cada situação. Desta forma, não há para essas enfermeiras um único e melhor modo para liderar. ${ }^{21}$

Em contrapartida, algumas literaturas tratam sobre a competência comunicativa, nas quais revela-se ainda como uma carência no perfil de enfermeiro, independentemente de sua área ou forma de atuação. ${ }^{22}$

\section{CONSIDERAÇÕES FINAIS}

A pesquisa identificou na percepção de enfermeiros acerca do tema liderança, a dificuldade em conciliar a assistência e a gerência concomitantemente durante seu trabalho. Os enfermeiros percebem a liderança como arte de 
influenciar pessoas e como gerenciar e coordenar equipes e fazem isso com mais segurança quando possuem habilidades em procedimentos técnicos.

Foi evidenciado no estudo, que durante a sua formação, o enfermeiro necessita de cenários e situações de aprendizado que permitam a apreensão da competência liderança, por meio do exercício das habilidades e atitudes profissionais que contribuem para o seu posterior desenvolvimento na prática profissional.

Espera-se que este estudo contribua para a reflexão sobre a liderança como uma competência gerencial, e para a formação de futuros enfermeiros com experiência instrumental suficiente para desencadear seu exercício no trabalho em equipe. Anseia-se pela conscientização por parte dos profissionais de enfermagem, na importância da liderança, pois quando empregada como uma competência gerencial pode ser útil não só na coesão de uma equipe, mas também como ferramenta auxiliadora nas mais diversas dimensões da prática profissional.

Conclui-se que, para desempenhar a liderança é necessário entendê-la como uma competência gerencial que permeia todas as dimensões do processo de trabalho do enfermeiro: cuidar, assistir, gerenciar, ensinar e pesquisar. Além disso, espera-se que este estudo contribua para propiciar reflexões e subsídios a novos estudos sobre liderança para enfermeiros e desta forma empoderá-los no desenvolvimento gerencial da profissão.

\section{REFERÊNCIAS}

1. Melo WS et al. Guia de atributos da competência política do enfermeiro: estudo metodológico. Rev Bras Enferm [internet] 2017 [acesso em 2018 Abr 25]; 70(3):552-60. Disponível em: < http://www.scielo.br/pdf/reben/v70n3/pt 0034-7167-reben-70-03-0526.pdf >. doi: http://dx.doi.org/10.1590/0034-7167-2016-0483.

2. Ministério da Educação (BR). Conselho Nacional de Educação. Resolução CNE/CES no 03/2001, de 7 de novembro de 2001. Institui as diretrizes curriculares nacionais do curso de graduação em Enfermagem. Diário Oficial da União, Brasília-DF, 09 nov. 2001. Seção 1, p. 37. Disponível em: $<$ http://portal.mec.gov.br/cne/arquivos/pdf/CES03.pdf >.

3. Silva VLS et al. Práticas de liderança em enfermagem hospitalar: uma self de enfermeiros gestores*. Rev Esc Enferm USP [internet] 2017 [acesso em 2018 Abr 26]; 207(51):e03206. Disponível em: < www.scielo.br/pdf/reeusp/v51/pt 1980-220X-reeusp-51-e03206.pdf>. doi: : http://dx.doi.org/10.1590/S1980-220X2016024403206

4. Lowen IMV et al. Competências gerenciais dos enfermeiros na ampliação da Estratégia Saúde da Família*. Rev Esc Enferm USP [internet] 2015 [acesso em 2018 Abr 27]; 49(6):967-973. Disponível em: 
<http://www.scielo.br/pdf/reeusp/v49n6/pt 0080-6234-reeusp-49-060967.pdf>. doi: http://dx.doi.org/10.1590/S0080-623420150000600013.

5. Amestoy SC et al. As percepções dos enfermeiros acerca da liderança. Rev Gaúcha Enferm [internet] 2009 [acesso em 2018 Abr 28]; 30(4):617-24. Disponível em: <http://www.scielo.br/pdf/rgenf/v30n4/a06v30n4.pdf>. doi: http://dx.doi.org/10.1590/S1983-14472009000400006.

6. Vale EG, Lima JR, Felli VEA. Programa de Atualização em Enfermagem (PROENFF) Gestão. Ciclo 2, vol. 2. Porto Alegre: Artmed/Panamericana, 2012, 11-39 p.

7. Ministério da Saúde (BR). Conselho Nacional de Saúde e Ética em Pesquisa. Resolução no 196/1996, de 10 de outubro de 1996. Diretrizes e normas regulamentadoras de pesquisa envolvendo seres humanos. Diário Oficial da União, Brasília-DF, 10 out. 1996. Disponível em: < http://bvsms.saude.gov.br/bvs/saudelegis/cns/1996/res0196 $10 \quad 10$ 1996.ht $\underline{\mathrm{ml}}>$.

8. Lefevre F, Lefreve AMC. Depoimentos e Discursos: uma proposta de análise em pesquisa social. Brasília: Líber, 2005, 97 p.

9. Lefevre F, Lefevre AMC. Discurso do sujeito coletivo: Representações sociais e intervenções comunicativas. Rev Texto Contexto Enferm [internet] 2014 [acesso em 2018 Fev 12]; 23(2):502-7. Disponível em: <http://www.scielo.br/pdf/tce/v23n2/pt 0104-0707-tce-23-02-00502.pdf>. doi: http://dx.doi.org/10.1590/0104-07072014000000014.

10. Góis RMO et al. Liderança em enfermagem: desafio nas práticas gerenciais a partir de um estudo bibliográfico. Ciências Biológicas e de Saúde [internet] 2015 [acesso em 2018 Abr 29]; 3(1):73-86. Disponível em: < https://periodicos.set.edu.br/index.php/cadernobiologicas/article/view/2429/1 $\underline{458}>$.

11. Antunes MJM, Felli VEA. Enfermagem e gestão do Sistema único de Saúde e da atenção básica. In: Valle EG (org.) Programa de Atualização em Enfermagem (PROENF Gestão) Porto Alegre: Artmed/ Panamericana, 2011.

12. Silva VLS, Camelo SHH. A competência da liderança em enfermagem: conceitos, atributos essenciais e o papel do enfermeiro líder. Rev. enferm UERJ [internet] 2013 [acesso em 28 Abr 2018]; 21(4):533-9. Disponível em: $<$ http://www.epublicacoes.ueri.br/index.php/enfermagemueri/article/view/10031/7817> . doi: https://doi.org/10.12957/reueri.2013.10031.

13. De Lima TL et al. Influência dos estilos de Liderança do Enfermeiro nas relações interpessoais da equipe de Enfermagem. Revista Enfermería Global [internet] 2011 [acesso em 2018 Abr 30]; 10(22):1-09. Disponível em: $<$ http://scielo.isciii.es/pdf/eg/v10n22/pt administracion3.pdf>. 
14. Lanzoni GMM, Meirelles BHS. Liderança do enfermeiro: uma revisão integrativa da literatura. Rev. Latino-Am. Enfermagem [internet] 2011 [acesso em 29 Abr 2018]; 19(3):8telas. Disponível em: $<$ http://www.scielo.br/pdf/rlae/v19n3/pt 26.pdf >. doi: http://dx.doi.org/10.1590/S0104-11692011000300026.

15. Almeida ML, Peres AM. Conhecimentos, habilidades e atitudes sobre a gestão dos formados de enfermagem de uma universidade pública brasileira. Invest Educ Enferm [internet] 2012 [acesso em 01 Mai 2018]; 30(1):66-76. Disponível em: < http://www.scielo.org.co/pdf/iee/v30n1/v30n1a08.pdf>.

16. Fugulin FMT, Gaidzinski RR, Castilho V. Dimensionamento de pessoal de Enfermagem em instituições de saúde. In: Kurcgant P (coord). Gerenciamento em Enfermagem. 3aㅡ ed. Rio de Janeiro: Guanabara Koogan, 2016, 212 p.

17. Meira MDD, Kurcgant P. Educação em enfermagem: avaliação da formação por egressos, empregadores e docentes. Rev Bras Enferm [internet] 2016 [acesso em 02 Mai 2018]; 69(1):10-5. Disponível em: < http://www.scielo.br/pdf/reben/v69n1/0034-7167-reben-69-01-0016.pdf>. doi: http://dx.doi.org/10.1590/0034-7167.2016690102i.

18. Fernandes U, Soares NV. Modelos de liderança adotados por enfermeiros de um hospital do Rio Grande do Sul ${ }^{1}$. J Nurs Health [internet] 2012 [acesso em 28 Abr 2018]; 2(1):38-43. Disponível em: < https://periodicos.ufpel.edu.br/ojs2/index.php/enfermagem/article/viewFile/3 452/2837>.

19. Peres L. Gerando envolvimento na equipe/Harvard Business School Press. Rio de Janeiro: Elsevier, 2007, 144 p.

20. Hartung SQ, Miller M. Communication and the healthy work environment: nurse managers' perceptions. J Nurs Adm [internet] 2013 [acesso em 27 Abr 2018]; 43(5):266-73. Disponível em: <https://www.ncbi.nlm.nih.gov/pubmed/23615368>. doi: http://dx.doi.org/10.1097/NNA.0b013e31828eeb3c.

21. Almeida ML et al. Instrumentos gerenciais utilizados na tomada de decisão do enfermeiro no contexto hospitalar. Texto Contexto Enferm [internet] 2011 [acesso em 28 Abr 2018]; 20(Esp):131-7. Disponível em: < http://www.scielo.br/pdf/tce/v20nspe/v20nspea17.pdf>. doi: http://dx.doi.org/10.1590/S0104-07072011000500017.

22. Treviso P et al. Competências do enfermeiro na gestão do cuidado. Rev. Adm. Saúde [internet] 2017 [acesso em 02 Mai 2018]; 17(69). Disponível em: < http://www.cqh.org.br/ojs-2.4.8/index.php/ras/article/view/59/77> doi: http://dx.doi.org/10.23973/ras.69.59. 
Recebido: 07 de maio de 2018. Publicado: 05 de junho de 2018

Correspondência: Vanessa Bordin. E-mail: vanessa.bordin@hotmail.com

Conflito de Interesses: os autores declararam não haver conflito de interesses.

(C) This is an Open Access article distributed under the terms of the Creative Commons Attribution License, which permits unrestricted use, distribution, and reproduction in any medium, provided the original work is properly cited 